\title{
PROFESSOR D. HOWELL PEREGRINE 30 December 1938 - 20 March 2007
}

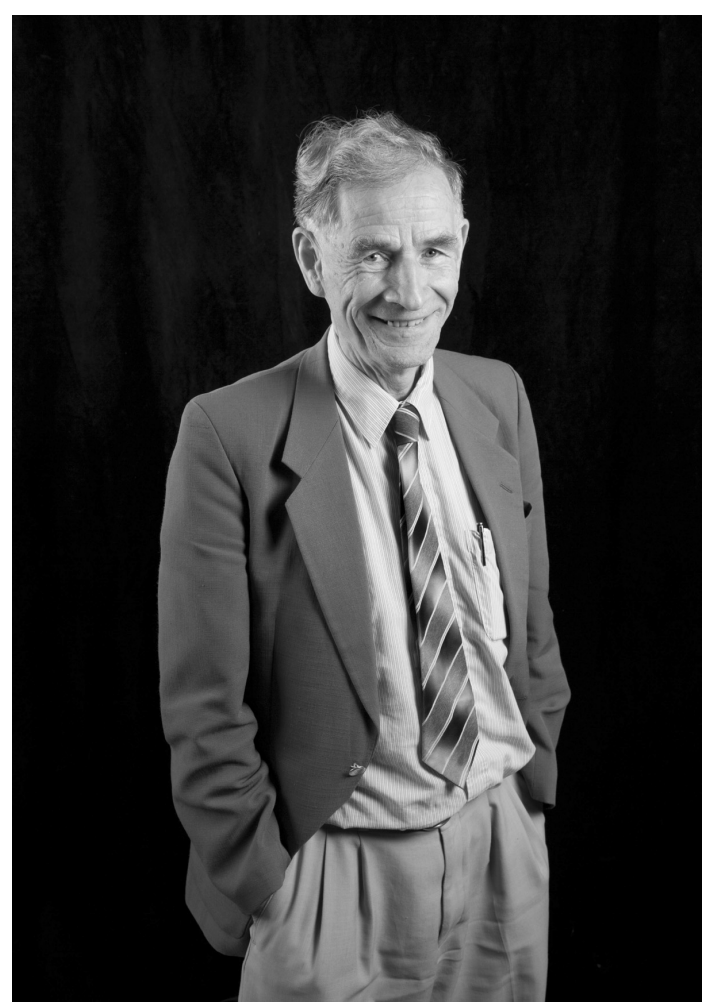

Photograph by Paul Groom. (C) University of Bristol

Howell Peregrine, who died on 20th March after a brief illness, had an exceptionally long and distinguished period of service for this Journal, first as Assistant Editor (1979-1980) then Associate Editor (1981-2007). In this capacity, he had editorial responsibility for some 50 papers every year, more than 1200 in total. This was a massive contribution to the continuing success of the Journal, to which it is appropriate and fitting that we pay grateful tribute.

Howell graduated from Oxford in 1960, and undertook his PhD research in DAMTP, Cambridge on the subject of nonlinear water wave propagation under the supervision of the late Professor Brooke Benjamin FRS. In 1964, he was appointed to a lectureship in the Department of Mathematics at Bristol University, in a strong fluid mechanics group under the leadership of the distinguished Professor Leslie Howarth FRS. Howell spent his entire career at Bristol, advancing through Readership to Professorship, and finally to Emeritus Professorship in 2005.

Howell published a distinguished series of papers on many aspects of water wave dynamics, notably on wave breaking, on the interaction of waves and currents in coastal areas and surf-zones, and on the large forces exerted by waves on ocean structures and harbour walls. His earliest papers in JFM, 'Calculations of the development of an undular bore' (vol. 25, 1966, pp. 321-330) and 'Long waves 
on a beach' (vol. 27, 1967, pp. 815-827) already showed conspicuous talent in the handling of nonlinear effects by finite-difference numerical techniques, a strategy of great originality at that time. From these early beginnings, Howell developed over the years to become a world authority on nonlinear wave dynamics, publishing more than 100 papers over a lifetime's work on this and related fields.

Howell's intense commitment to his subject was complemented by an engaging ability to inspire students, both undergraduate and graduate, and to collaborate with the many post-docs and visitors at Bristol over more than 40 years. I was myself privileged to serve in the Mathematics Department at Bristol from 1977 to 1980, and to witness at close quarters how effective and conscientious Howell was in every aspect of his multifarious responsibilities there. I recall with particular pleasure the expeditions that he organised for new research students to see the famous Severn Bore, usually at about 5 o'clock in the morning, giving a running commentary on the associated dynamics.

Howell was a familiar figure at international meetings, and particularly at Congresses and Symposia of IUTAM, for which he had served on the Fluid Mechanics Panel since 2000. In this sphere also, he will be sorely missed.

Howell was a brilliant photographer of natural phenomena. We were delighted that he allowed us to use one of his wave photographs in one of the Millennium posters 'Maths Makes Waves' of the Isaac Newton Institute. Howell himself made waves in his impact on fluid mechanics and in a life of outstanding devotion to his subject.

H. K. MOFFatT 